\title{
ANALISIS PENGARUH KONSUMSI BBM KENDARAAN PENUMPANG 1200 CC TERHADAP LALU LINTAS KOTA SEMARANG
}

\author{
Muhamad Surifil Anam*, Tabah Priangkoso dan Darmanto \\ Jurusan Teknik Mesin, Fakultas Teknik, Universitas Wahid Hasyim Semarang \\ Jl. Menoreh Tengah X/22, Sampangan Semarang 50236 \\ *Email : anamsurifil@gmail.com
}

\begin{abstract}
Abstrak
Bahan bakar yang ada di Indonesia terdiri dari berbagai jenis, jenis-jenis bahan bakar tersebut disesuaikan dengan kebutuhan teknologi yang diterapkan di kendaraan. Sampai saat ini jenis bahan bakar motor bensin ada 4 jenis, yaitu : premium, Pertalite, Pertamax dan Pertamax Turbo, berbagai jenis bahan bakar tersebut memiliki karakteristik tersendiri,. Performa dari motor kendaraan dipengaruhi oleh beberapa faktor, diantaranya adalah jenis bahan bakar yang digunakan. Penelitian ini bertujuan untuk mengetahui pengaruh konsumsi tiap bahan bakar yang berbeda yaitu Pertalite, Pertamax dan Pertamax Turbo pada kendaraan penumpang terhadap lalu lintas di kota Semarang. Pengujian masing-masing jenis bahan bakar di kendaraan penumpang 1200 CC dengan bantuan sistem komputer OBD II ELM 327Mini yang akan menghasilkan data konsumsi bahan bakar pada kendaraan melalui aplikasi pada smartphone. Hasil penelitian menunjukkan penggunaan bahan bakar Pertamax mencapai jarak tempuh terjauh yaitu sebesar $20,49 \mathrm{Km} / \mathrm{L}$ pada kecepatan $50 \mathrm{Km} / \mathrm{h}$, untuk bahan bakar Pertamax Turbo mampu mencapai jarak 18,79 pada kecepatan $30 \mathrm{Km} / \mathrm{h}$ posisi gigi 4, sedangkan bahan bakar Pertalite hanya mampu menempuh jarak maksimal sebesar $16,74 \mathrm{Km} / \mathrm{L}$ pada kecepatan $36 \mathrm{Km} / \mathrm{h}$.
\end{abstract}

Kata kunci: Konsumsi bahan bakar, Pertalite, Pertamax, Pertamax Turbo

\section{PENDAHULUAN}

Alat transportasi diciptakan manusia untuk memenuhi kebutuhan dan mempermudah pekerjaan dari manusia. Kendaraan di Indonesia memiliki berbagai macam jenis diantaranya kendaraan roda empat untuk kebutuhan seharihari, Mesin kendaraan penumpang memerlukan jenis bahan bakar yang sesuai dengan desain mesin itu sendiri agar dapat bekerja dengan optimal. Jenis bahan bakar tersebut biasanya diwakili dengan angka oktan (RON).

Semakin tinggi nilai oktan maka harga per liternya umumnya semakin tinggi (mahal). Namun belum tentu bagan bakar dengan oktan yang lebih tinggi akan menghasilkan tenaga yang lebih tinggi. Tapi dengan perbandingan nilai RON tersebut akan berpengaruh dengan mesin mobil apakah sesuai dengan performa mesin yang akan meningkatkan dalam arti bahan bakar bisa terbakar dengan sempurna atau malah sebaliknya.

Bahan bakar yang beredar di Indonesia terdiri dari berbagai jenis, jenis-jenis bahan bakar tersebut disesuaikan dengan teknologi yang diterapkan pada kendaraan. Sampai saat ini ada 4 jenis bahan bakar motor bensin yaitu: Premium, Pertalite, Pertamax dan Pertamax Turbo. Berbagai jenis bahan bakar tersebut memiliki karakteristik tersendiri sehingga konsumen memiliki pilihan dalam menentukan bahan bakar yang digunakan, sesuai dengan kendaraan yang digunakan.

Peningkatan Kinerja motor bakar terus dikembangkan dengan melakukan penelitian dari berbagai aspek. Misalnya penelitian tentang bi-fuel dengan bioethanol (Nailul, 2017), menambahkan bahan bakar gas pada kendaraan (Nugroho, 2020) dan aspek lainnya misalnya dari cara mengemudi kendaraan serta parameter lain (N. Sinaga, 2011).

Mobil penumpang merupakan jenis transportasi yang sangat diminati di Indonesia. Potensi penghematan konsumsi bahan bakar dari mobil penumpang dapat dilakukan dengan membuat sebuah persamaan konsumsi bahan bakar agar lebih efisien untuk mobil penumpang berbahan bakar bensin sistem injeksi elektronik (EFI) (N. Sinaga, 2013) atau dengan metode lainnya. Penelitian ini bertujuan untuk mengetahui pengaruh jenis BBM kendaraan penumpang 1200 CC terhadap konsumsi bahan bakar di jalan kota. Berdasarkan pengaruh yang ada tersebut akan diketahui tingkat efektivitas penggunaan bahan bakar pada kendaraan penumpang $1200 \mathrm{CC}$ di jalan kota dari setiap bahan bakar. 


\section{METODE PENELITIAN}

Metode yang dipakai untuk menyelesaikan penelitian analisis pengaruh Bahan bakar terhadap konsumsi bahan bakar kendaraan penumpang dapat diselesaikan seperti gambar 1. Penelitian ini dilakukan dengan cara membandingkan konsumsi bahan bakar. Setiap bahan bakar akan dilakukan 3 kali pengujian untuk setiap bahan bakar dengan rute dan beban yang sama. Peralatan yang digunakan dalam penelitian ini antara lain : Scanner OBD II ELM 327 Mini, alat ini berguna untuk pemindaian nirkabel untuk semua mesin sehingga dapat terdeteksi dari kinerja mesin secara real time. Smartphone, digunakan untuk merekam data output dati OBD II ELM 327 Mini dengan Aplikasi melalui bluetooth. Aplikasi OBD Fusion, digunakan untuk merekam data dari Scanner OBD II ELM 327 Mini yang dihubungkan melalui bluetooth. Kendaraan dengan sistem EFI yang sudah dilengkapi dengan slot OBD II dan untuk penelitian ini digunakan kendaraan penumpang kapasitas silinder $1200 \mathrm{cc}$.

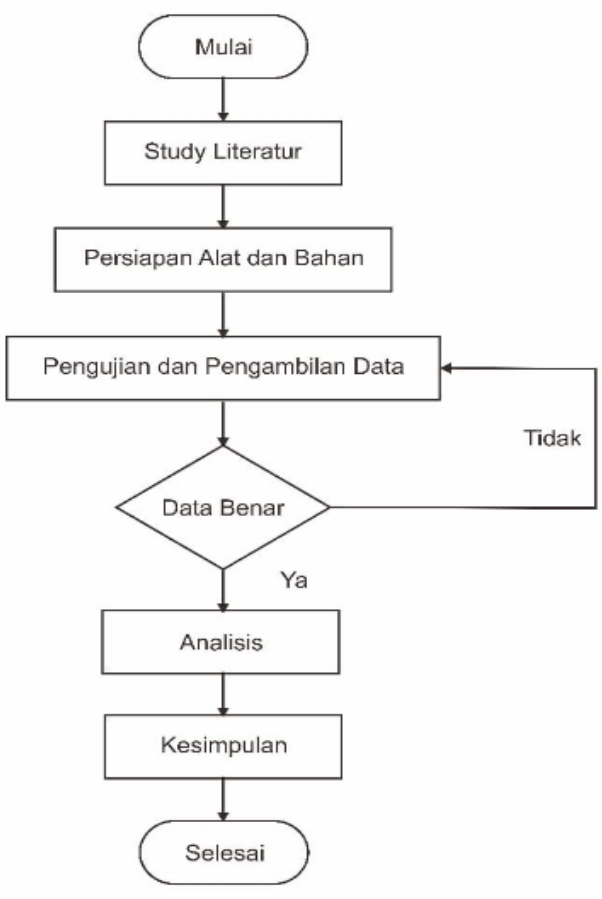

Gambar 1. Flow chart penelitian

HASIL DAN PEMBAHASAN

Konsumsi Bahan Bakar Pertalite

Konsumsi bahan bakar Pertalite pada pengujian kendaraan penumpang $1200 \mathrm{cc}$ yang sudah dilakukan mendapatkan hasil sebagai berikut.

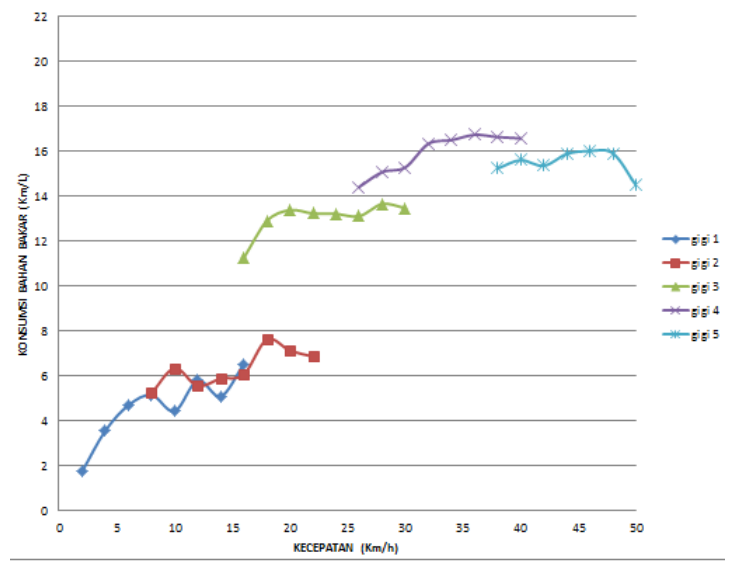

\section{Gambar 2. Grafik konsumsi bahan bakar Pertalite}

Dari gambar 2. terlihat bahwa bahan bakar Pertalite menunjukkan semakin tinggi kecepatan dan gigi maka konsumsi bahan bakar cenderung lebih rendah, pada gigi 1 dengan kecepatan $2 \mathrm{Km} / \mathrm{h}$ hanya mampu menempuh jarak $1,76 \mathrm{Km} / \mathrm{L}$ ini menunjukkan bahwa penggunaan bahan bakar paling tinggi terjadi pada gigi 1 kecepatan $2 \mathrm{Km} / \mathrm{h}$. Pada gigi 2 untuk penggunaan bahan bakar paling tinggi terjadi pada kecepatan $8 \mathrm{Km} / \mathrm{h}$ dengan konsumsi bahan bakar 5,24 Km/L.

\section{Konsumsi bahan bakar Pertamax}

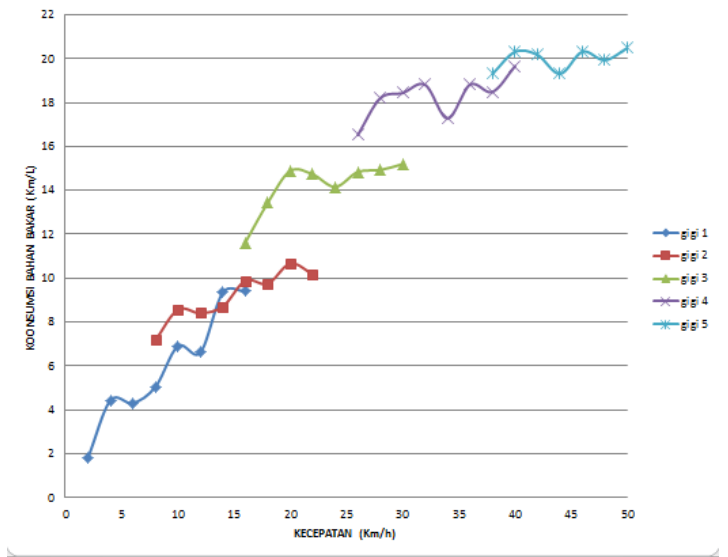

\section{Gambar 3. Grafik konsumsi bahan bakar Pertamax}

Pada pengujian bahan bakar Pertalite penggunaan bahan bakar paling rendah adalah pada gigi 4 kecepatan $36 \mathrm{Km} / \mathrm{h}$ dengan penggunaan bahan bakar sebesar $16,74 \mathrm{Km} / \mathrm{L}$, selanjutnya untuk penggunaan paling rendah yaitu pada kecepatan 13,66 Km/L dan 6,87 $\mathrm{Km} / \mathrm{L}$ pada posisi gigi $5,3,2$. Ini terjadi karena 
memang pengujian pada gigi 5 di jalan raya sangat jarang mencapai titik optimal.

Dari hasil pengujian grafik konsumsi bahan bakar Pertamax diatas dapat disimpulkan bahwa bahan bakar Pertamax mengalami konsumsi bahan bakar semakin rendah seiring bertambahnya kecepatan dan posisi gigi, pada gigi 1 kecepatan $2 \mathrm{Km} / \mathrm{h}$ hanya mampu menempuh jarak $1,82 \mathrm{Km} / \mathrm{L}$ pada gigi $2,3,4$, 5, konsumsi bahan bakar tertinggi pada kecepatan .8, 16, 26,dan $38 \mathrm{Km} / \mathrm{h}$ dengan konsumsi tertinggi pada setiap gigi yaitu 7,18 $\mathrm{Km} / \mathrm{L}, 11,62 \mathrm{Km} / \mathrm{L}, 16,53 \mathrm{Km} / \mathrm{L}$ dan 19,31 $\mathrm{Km} / \mathrm{L}$.

Pada pengujian bahan bakar Pertamax, jarak terjauh yang bisa ditempuh yaitu sebesar $20,49 \mathrm{Km} / \mathrm{L}$ dengan kecepatan tempuh $50 \mathrm{Km} / \mathrm{h}$ sedangkan pada gigi 4, 3 dan 2 jarak terjauh yaitu $19,66 \mathrm{Km} / \mathrm{L}, 15,2 \mathrm{Km} / \mathrm{L}$ dan $10,67 \mathrm{Km} / \mathrm{L}$ pada kecepatan $40 \mathrm{Km} / \mathrm{h}, 30 \mathrm{Km} / \mathrm{h}$, dan 20 $\mathrm{Km} / \mathrm{h}$.

\section{Konsumsi bahan bakar Pertamax Turbo}

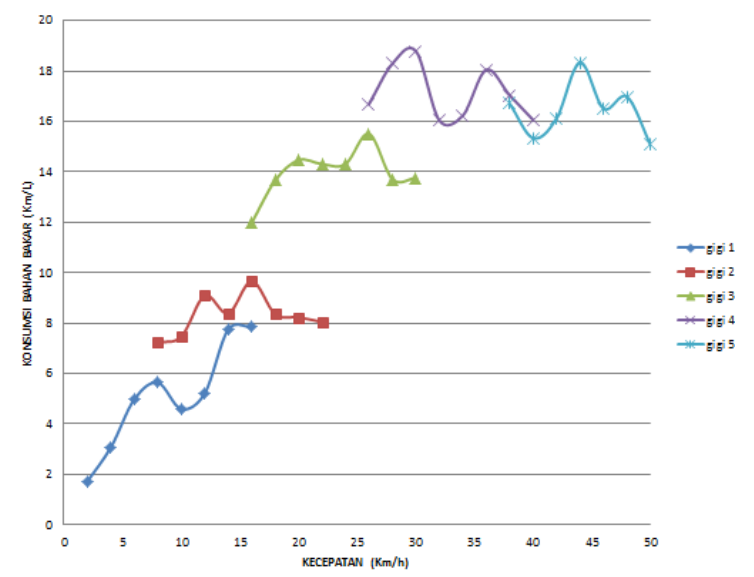

\section{Gambar 4. Grafik konsumsi bahan bakar Pertamax Turbo}

Dari gambar 4. dapat dilihat bahwa bahan bakar Pertamax Turbo mengalami konsumsi bahan bakar semakin rendah atau mengalami jarak tempuh yang semakin panjang seiring bertambahnya kecepatan dan posisi gigi, pada gigi 1 kecepatan $2 \mathrm{Km} / \mathrm{h}$ hanya mampu menempuh jarak $1,73 \mathrm{Km} / \mathrm{L}$ pada gigi $2,3,4$, 5, konsumsi bahan bakar tertinggi pada kecepatan .8, 16, 40,dan $50 \mathrm{Km} / \mathrm{h}$ dengan konsumsi tertinggi atau jarak terpendek pada setiap gigi yaitu 7,23 Km/L, 11,98 Km/L, 16,06 $\mathrm{Km} / \mathrm{L}$ dan $15,09 \mathrm{Km} / \mathrm{L}$. Pada pengujian bahan bakar Pertamax Turbo seperti pada gambar 4., jarak terjauh yang bisa ditempuh yaitu sebesar
$18,79 \mathrm{Km} / \mathrm{L}$ dengan kecepatan tempuh $30 \mathrm{Km} / \mathrm{h}$ pada gigi 4 sedangkan pada gigi 5, 3 dan 2 jarak terjauh yaitu $18,34 \mathrm{Km} / \mathrm{L}, 15,57 \mathrm{Km} / \mathrm{L}$ dan 9,67 $\mathrm{Km} / \mathrm{L}$ pada kecepatan $44 \mathrm{Km} / \mathrm{h}, 26 \mathrm{Km} / \mathrm{h}$, dan $16 \mathrm{Km} / \mathrm{h}$.

\section{Konsumsi bahan bakar pada posisi 1}

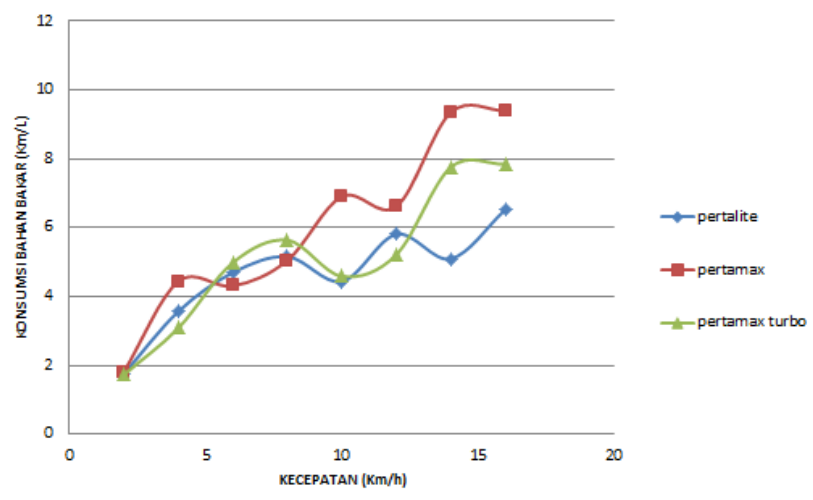

\section{Gambar 5 Grafik konsumsi bahan bakar pada posisi gigi 1}

Konsumsi bahan bakar pada posisi gigi 1 disajikan pada gambar 5. pada kecepatan 2 $\mathrm{Km} / \mathrm{h}$ mampu menempuh jarak $1,73 \mathrm{Km} / \mathrm{L}$, jarak yang ditempuh lebih pendek dibandingkan dengan bahan bakar Pertalite dan Pertamax yang mampu menempuh jarak berturut-turut yaitu $1,76 \mathrm{Km} / \mathrm{L}, 1,83 \mathrm{Km} / \mathrm{L}$. Pada pengujian bahan bakar posisi gigi 1, jarak terjauh untuk konsumsi bahan bakar tertinggi yaitu Pertamax dengan mampu menempuh jarak $9,4 \mathrm{Km} / \mathrm{L}$, pada kecepatan $16 \mathrm{Km} / \mathrm{L}$ sedangkan pada Pertalite dan Pertamax Turbo hanya mampu menempuh jarak $6,53 \mathrm{Km} / \mathrm{L}$ dan $7,85 \mathrm{Km} / \mathrm{L}$ pada kecepatan yang sama yaitu $16 \mathrm{Km} / \mathrm{h}$.

\section{Konsumsi bahan bakar pada posisi gigi 2}

Dari data gambar 6. Menunjukkan bahwa pada kecepatan $8 \mathrm{Km} / \mathrm{h}$ mampu menempuh jarak $5,24 \mathrm{Km} / \mathrm{L}$, jarak yang ditempuh lebih pendek dibandingkan dengan bahan bakar Pertamax dan Pertamax Turbo yang mampu menempuh jarak berturut-turut yaitu 7,18 $\mathrm{Km} / \mathrm{L}, 7,23 \mathrm{Km} / \mathrm{L}$. Pada pengujian bahan bakar posisi gigi 2, jarak terjauh untuk konsumsi bahan bakar tertinggi yaitu Pertamax dengan mampu menempuh jarak 10,67 Km/L, pada kecepatan $20 \mathrm{Km} / \mathrm{L}$ sedangkan pada Pertalite dan Pertamax Turbo hanya mampu menempuh $7,14 \mathrm{Km} / \mathrm{L}$ dan $8,23 \mathrm{Km} / \mathrm{L}$ pada kecepatan yang sama yaitu $20 \mathrm{Km} / \mathrm{h}$. 


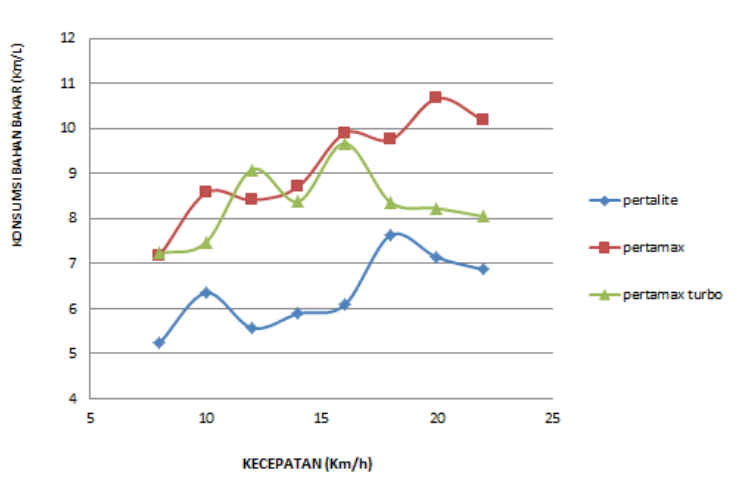

Gambar 6. Grafik konsumsi bahan bakar pada posisi gigi 2

\section{Konsumsi bahan bakar pada posisi gigi 3}

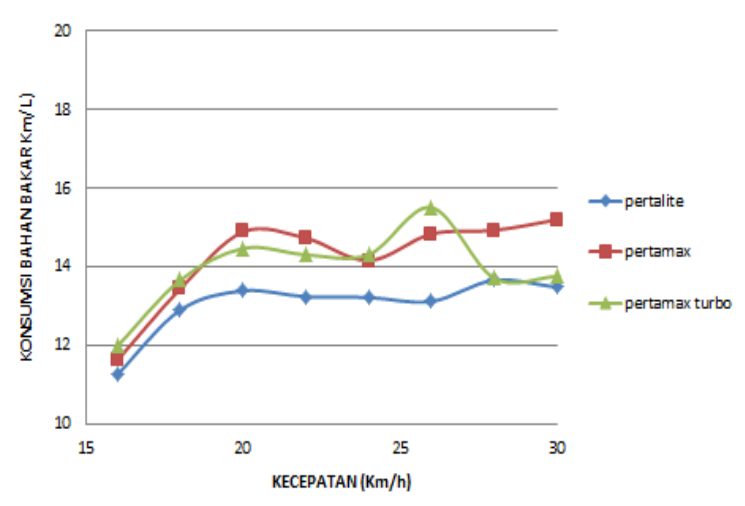

\section{Gambar 7. Grafik konsumsi bahan bakar pada posisi gigi 3}

Dari data hasil grafik diatas konsumsi bahan bakar pada posisi gigi 3 disimpulkan bahwa bahan bakar Pertalite, pada kecepatan 16 $\mathrm{Km} / \mathrm{h}$ mampu menempuh jarak 11,26 Km/L, jarak yang ditempuh lebih pendek dibandingkan dengan bahan bakar Pertamax dan Pertamax Turbo yang mampu menempuh jarak berturutturut yaitu $11,62 \mathrm{Km} / \mathrm{L}, 11,28 \mathrm{Km} / \mathrm{L}$.

Konsumsi bahan bakar diuji pada posisi gigi 3, jarak terjauh untuk konsumsi bahan bakar tertinggi yaitu Pertamax dengan mampu menempuh jarak $15,2 \mathrm{Km} / \mathrm{L}$, pada kecepatan 30 $\mathrm{Km} / \mathrm{L}$ sedangkan pada Pertalite dan Pertamax Turbo hanya mampu menempuh 13,48 Km/L dan $13,76 \mathrm{Km} / \mathrm{L}$ pada kecepatan yang sama yaitu $30 \mathrm{Km} / \mathrm{h}$.

\section{Konsumsi bahan bakar pada posisi gigi 4}

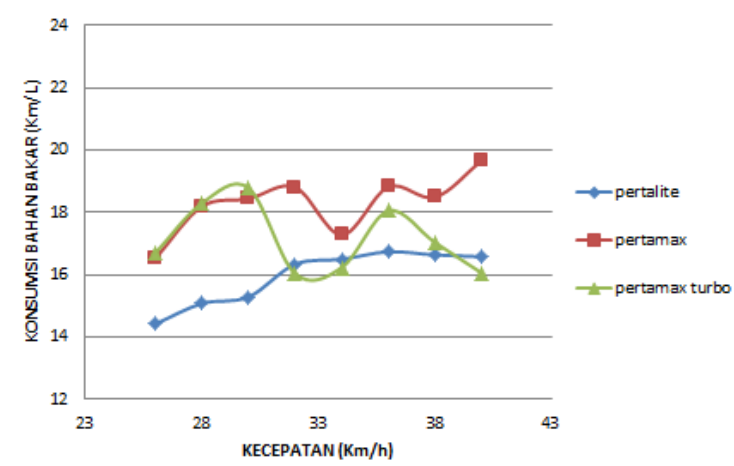

\section{Gambar 8. Grafik konsumsi bahan bakar pada posisi gigi 4}

Pada posisi gigi 4 seperti terlihat pada gambar 8. Menunjukkan semua kecepatan mengalami penggunaan bahan bakar paling tinggi dengan tingkat yang paling tinggi yaitu pada kecepatan $26 \mathrm{Km} / \mathrm{h}$ dengan tingkat konsumsi bahan bakar 14,42 Km/L, jarak yang ditempuh lebih pendek dibandingkan dengan bahan bakar Pertamax dan Pertamax Turbo yaitu sebesar 16,52 Km/L dan 16,69 Km/L.

Pada posisi gigi 4 untuk yang paling rendah konsumsi bahan bakar yaitu bahan bakar Pertamax pada kecepatan $40 \mathrm{Km} / \mathrm{h}$ dengan konsumsi bahan bakar mencapai jarak tempuh 19,66 Km/L, sedangkan pada Pertalite dan Pertamax Turbo hanya mampu menempuh $16,58 \mathrm{Km} / \mathrm{L}$ dan $16,06 \mathrm{Km} / \mathrm{L}$ pada kecepatan yang sama yaitu $40 \mathrm{Km} / \mathrm{h}$.

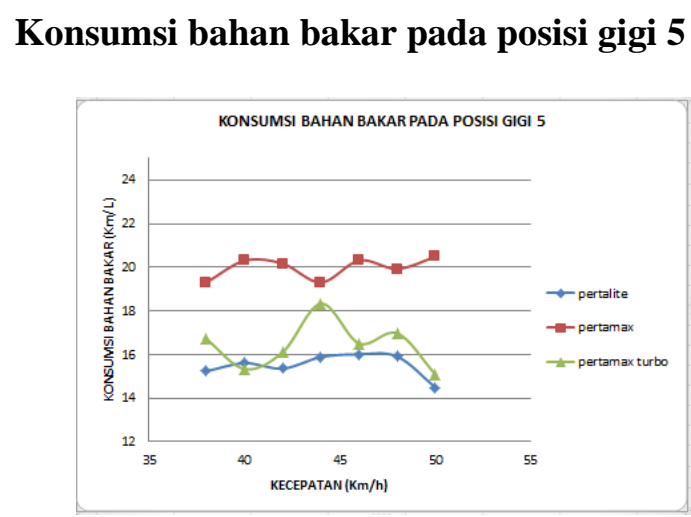

\section{Gambar 9. Grafik konsumsi bahan bakar pada posisi gigi 5}

Pertalite pada semua kecepatan mengalami penggunaan bahan bakar paling tinggi dengan tingkat yang paling tinggi yaitu pada kecepatan $50 \mathrm{Km} / \mathrm{h}$ dengan tingkat konsumsi bahan bakar $15,09 \mathrm{Km} / \mathrm{L}$, jarak yang ditempuh lebih pendek 
dibandingkan dengan bahan bakar Pertamax dan Pertamax Turbo yaitu sebesar 20,49 Km/L dan $15,09 \mathrm{Km} / \mathrm{L}$ (lihat gambar 9.).

\section{Rata-rata konsumsi bahan bakar di setiap gigi}

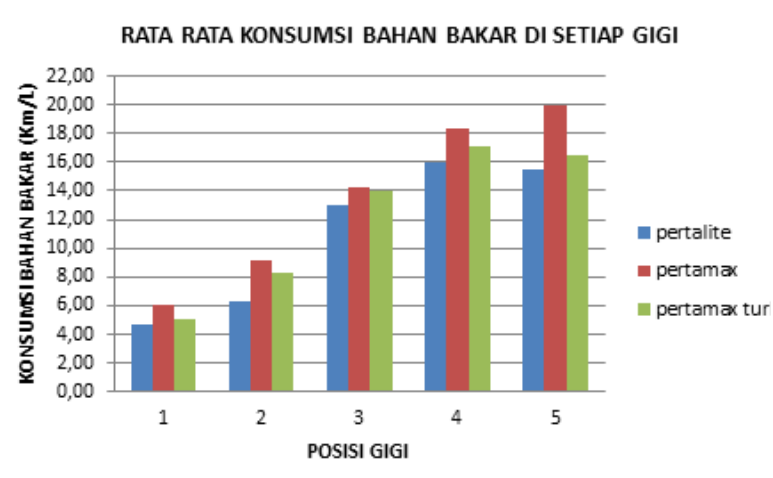

\section{Gambar 10. Rata-rata konsumsi bahan bakar di setiap gigi}

Dari hasil grafik diatas dapat diambil kesimpulan dimana peningkatan kecepatan pada setiap posisi gigi menunjukkan kecenderungan penurunan konsumsi bahan bakar kendaraan. Kecenderungan ini terjadi pada penggunaan ketiga bahan bakar. Konsumsi bahan bakar lebih hemat pada gigi-gigi yang lebih tinggi dibanding gigi yang lebih rendah pada kecepatan yang sama.

\section{KESIMPULAN}

Hasil analisis pengaruh konsumsi bahan bakar terhadap lalu lintas Kota Semarang dengan perbandingan bahan bakar Pertalite, Pertamax, Pertamax Turbo pada kendaraan penumpang tahun pembuatan 2019 didapatkan hasil peningkatan kecepatan pada setiap posisi gigi menunjukkan kecenderungan penurunan konsumsi bahan bakar kendaraan, kecenderungan ini terjadi pada penggunaan ketiga bahan bakar, konsumsi bahan bakar lebih hemat pada gigi-gigi yang lebih tinggi dibanding gigi yang lebih rendah pada kecepatan yang sama.

Jenis bahan bakar berpengaruh terhadap konsumsi bahan bakar kendaraan penumpang. Bahan bakar jenis Pertalite menjadi bahan bakar yang paling boros digunakan sedangkan Pertamax merupakan bahan bakar paling rendah dikonsumsi untuk kecepatan dan posisi gigi yang sama. Untuk bahan bakar paling hemat yaitu pada bahan bakar Pertamax dengan jarak tertinggi yaitu sebesar $20,49 \mathrm{Km} / \mathrm{L}$ pada kecepatan $50 \mathrm{Km} / \mathrm{h}$, untuk Pertamax Turbo jarak paling jauh didapat pada kecepatan 30 $\mathrm{Km} / \mathrm{h}$ yaitu sebesar $18,79 \mathrm{Km} / \mathrm{L}$ dan untuk Pertalite jarak terjauh yang di tempuh adalah $16,74 \mathrm{Km} / \mathrm{L}$ pada kecepatan $36 \mathrm{Km} / \mathrm{h}$.

\section{Saran}

Untuk penelitian selanjutnya tentang pengaruh konsumsi bahan bakar pada kendaraan penumpang di jalan Kota perlu diperhatikan untuk cara mengemudi dengan kondisi dan cara berkendara yang sama, karena sangat berpengaruh terhadap hasil dari analisis perbedaan konsumsi pada tiap bahan bakar, mengingat informasi ini sangat diperlukan masyarakat dalam berkendara agar berada pada kecepatan dan posisi gigi yang paling hemat.

\section{DAFTAR PUSTAKA}

Agus Nailul, 2017. Analisis Pengaruh Penambahan Bioethanol Pada Bahan Bakar Minyak Terhadap Performance Dan Konsumsi Bahan Bakar Sepeda Motor Yamaha Mio 115cc FI, Tugas Akhir, T. Mesin, Fakultas Teknik, Universitas Wahid Hasyim, Semarang.

N. Sinaga, T. Priangkoso, D. Widayana, dan K.

Abdurrohman., 2011. Kaji Eksperimental

Pengaruh Beberapa Parameter

Berkendaraan Terhadap Tingkat

Konsumsi Bahan Bakar Kendaraan Penumpang Kapasitas Silinder 1500 2000 CC, SNTTM X, Malang.

Nugroho, Agung, Walujo, Ika Bayu, Sinaga, N. (2020). Kaji Eksperimental Penggunaan Dual Fuel Pada Mesin Diesel Berbahan Bakar Dexlite -LPG. Momentum, 16(1), 75-79.

S. Nazaruddin., Purnomo, S.J., Dewangga, A., 2013. Pengembangan Model Persamaan Konsumsi Bahan Bakar Efisien Untuk Mobil Penumpang Berbahan Bakar Bensin Sistem Injeksi Elektronik (EFI), FT, Universitas Diponegoro 